\title{
Evaluación del bullying como victimización: Estructura, fiabilidad y validez del Cuestionario de Acoso entre Iguales (CAI)
}

\author{
Ana M. Magaz 1 , Paloma Chorot ${ }^{2}$, Miguel A. Santed ${ }^{2}$, Rosa M. Valiente ${ }^{2}$ y Bonifacio Sandín ${ }^{2}$ \\ ${ }^{1}$ Hospital Gregorio Marañón, Madrid, España \\ ${ }^{2}$ Universidad Nacional de Educación a Distancia (UNED), Madrid, España
}

\begin{abstract}
Resumen: El objetivo del presente estudio consistió en proporcionar evidencia preliminar sobre la validación del Cuestionario de Acoso entre Iguales (CAI). Examinamos la estructura factorial, la fiabilidad y la validez convergente y discriminante de la escala de Conductas de Acoso (CAI-CA) en una muestra de niños y adolescentes. Los análisis factoriales exploratorios y confirmatorios constataron una estructura de siete factores no correlacionados que se corresponden con los siguientes tipos de bullying: maltrato físico, maltrato verbal, exclusión social directa, exclusión social indirecta, amenazas, ciberbullying, y agresión basada en objetos. Los resultados apoyan la validez factorial, la consistencia interna, y la validez convergente y discriminante del cuestionario. Los datos sugieren que el CAI-CA puede ser una herramienta apropiada para evaluar el bullying de victimización tanto en contextos de investigación como clínicos.
\end{abstract}

Palabras clave: CAI; bullying; acoso entre iguales; victimización; ciberbullying; evaluación; niños; adolescentes.

Assessment of bullying victimization: Structure, reliability and validity of the Cuestionario de Acoso entre Iguales (CAI; Peer Bullying Questionnaire)

\begin{abstract}
The aim of the present study was to provide preliminary evidence concerning validation of the Cuestionario de Acoso entre Iguales (CAI) [Peer Bullying Questionnaire]. We examined the factor structure, reliability and convergent and discriminant validity of the Conductas de Acoso (CAI-CA) scale [Bullying Behaviors] in a sample of school-aged children and adolescents. Exploratory and confirmatory factor analyses provided support for a structure of seven uncorrelated factors which correspond to the following kinds of bullying: physical aggression, verbal aggression, direct social exclusion, indirect social exclusion, threats, cyberbullying, and aggression based on physical objects. Results provide support for factorial validity, internal consistency, and convergent and discriminant validity of the questionnaire. Data suggest that the CAI-CA is an appropriate assessment instrument of bullying victimization that may be a suitable tool for research and clinical purposes.
\end{abstract}

Keywords: CAI; bullying; victimization; cyberbullying; assessment; children; adolescents.

\section{Introducción}

El bullying, o acoso entre iguales en el contexto escolar y extraescolar, no es un concepto unitario, pudiendo ser definido desde distintos puntos de vista in-

Recibido: 15 septiembre 2015; aceptado: 12 diciembre 2015 Correspondencia: Paloma Chorot, Universidad Nacional de Educación a Distancia (UNED), Facultad de Psicología, Juan del Rosal 10, 28040 Madrid, España.

Correo-e: pchorot@psi.uned.es cluidos desde la víctima y desde el agresor. El bullying como victimización (i.e., desde el punto de vista de la víctima) ha sido descrito como la situación en la que un niño o adolescente está expuesto a acciones negativas por parte de uno o más de sus compañeros (Olweus, 1973). Se entiende por acciones negativas aquellas que de manera intencionada intentan herir o producir daño o malestar. Suele asumirse que se trata de un comportamiento agresivo, repetido en el tiempo, y que se da en el seno de una relación interpersonal asimétrica (Smith y Sharp, 1994). 
El bullying como victimización es un fenómeno bastante común entre los niños y adolescentes en el contexto escolar. En este sentido, se han sugerido datos sobre su prevalencia muy variados, oscilando entre un 5\% y un 50\% (Hansen, Steenber, Palic y Elklik, 2012), aunque la mayor parte de los casos parecen distribuirse entre el $20 \%$ y el $30 \%$, y los casos graves de victimización entre el 3\% y el 10\% (Fu, Land, Lamb, 2013; Magaz, 2012; Magaz, Chorot, Sandín, Santed y Valiente, 2011; Solberg y Olweus, 2003; Undheim y Sund, 2010). Estos estudios tienden a indicar que la mayoría de los casos de niños victimizados son varones, el tipo de acoso más frecuente es el verbal, y el contexto donde este tipo de acoso suele ser más habitual es el patio del colegio.

Recientemente se ha producido un elevado interés por el denominado ciberbullying, o bullying a través del uso de las tecnologías de la información y comunicación (internet, teléfonos móviles [smartphone], redes sociales, etc.) (Slonje, Smith, y Frisén, 2013). Respecto a esta nueva modalidad de acoso entre iguales, se ha señalado que entre un $40 \%$ y un 55\% de los escolares están implicados bien como víctimas, o como agresores u observadores, y entre un $20 \%$ y un $50 \%$ informan de experiencias de victimización, aunque los casos graves de víctimas de ciberbullying no suele superar el 7\% (Garaigordobil, 2014). Considerando las tasas de prevalencia referidas para el bullying en general, estos valores resultan excesivamente sobreestimados.

Un aspecto importante para la investigación e intervención del bullying concierne a su evaluación. Aunque se han venido utilizando diversos tipos de procedimientos con este propósito, generalmente ha predominado la utilización de instrumentos de autoinforme, los procedimientos sociométricos, y la observación de la conducta. En el caso del bullying de victimización, tienen un valor especial los procedimientos de autoinforme, ya que posibilitan evaluar la percepción que tiene el niño del acoso, algo más difícil de cuantificar mediante otros métodos de evaluación más objetivos. Por otra parte, constituyen una herramienta de evaluación rápida y sencilla de aplicar y analizar, que cuantifica la introspección que tiene el alumno respecto al maltrato sufrido, además de representar un bajo coste económico. En este sentido, diversos autores coinciden en destacar que los procedimientos de autoinforme, cumplimentados de forma anónima, proporcionan una estimación bastante fiable y valida sobre la prevalencia del bullying y sobre otros aspectos relacionados (Ahmad y Smith, 1990).

El Bully/Victim Questionaire de Olweus (OBVQ; Olweus, 1986) suele considerarse como el primer cuestionario diseñado para evaluar el acoso escolar, habiendo sido también el más utilizado a nivel internacional (Nan- sel et al., 2001). El instrumento original apareció en 1986 y consistía en 56 ítems. Posteriormente el autor revisó el cuestionario en varias ocasiones (Olweus, 1996), reduciendo el número de ítems a 36 y describiendo diferentes formas de bullying (agresión verbal y física, y exclusión social). Este instrumento, aparte de ser el más utilizado y validado internacionalmente, ha servido de referencia en la construcción de la mayoría de los procedimientos de evaluación del bullying que existen actualmente.

En los últimos años se han venido desarrollando en España y en otros países diversos cuestionarios de autoinforme para evaluar diferentes facetas asociadas al bullying (Magaz, 2012), entre las que se incluyen las modalidades de acoso (Mynard y Joseph, 2000), las características y/o perfiles de los agresores, los observadores y las víctimas (Avilés, 1999; Ortega, Mora, y Mora-Merchán, 1995), los contextos escolares y extraescolares (Díaz-Aguado, Martínez, y Martín, 2004), los daños psicológicos asociados (Piñuel y Oñate, 2006), y el ciberbullying (Avilés, 2010; Buelga, Cava, y Musito, 2010; Garaigordobil, 2014; Genta et al., 2012).

En general los diferentes cuestionarios de autoinforme del bullying son bastante heterogéneos, enfatizando más unos aspectos que otros en función de los intereses de los autores. Considerando la gran relevancia que tiene sobre la salud y el desarrollo del niño y del adolescente la propia percepción de victimización de bullying que estos puedan experimentar, especialmente en el ámbito académico, se echa de menos un instrumento centrado específicamente en esta faceta, así como también en los diferentes aspectos directamente relacionados. Con objeto de cubrir este vacío actual en la literatura sobre la investigación del bullying, llevamos a cabo el desarrollo del Cuestionario de Acoso entre Iguales (CAI), un nuevo instrumento centrado en el bullying como victimización (Magaz, 2012; Magaz et al., 2011). Las dimensiones (escalas) y características de este cuestionario se resumen en la Tabla 1.

Como puede apreciarse en la tabla, el CAI consta de 7 escalas y diversas subescalas. Merece la pena resaltar que, aparte de la escala de conductas de acoso (incluye varios tipos de maltrato, así como también conductas de acoso asociadas al género), el cuestionario evalúa otros aspectos relevantes como los escenarios donde se produce el acoso, los personajes implicados (defensores, observadores y agresores), las estrategias de afrontamiento, los posibles confidentes, y los síntomas del trastorno de estrés postraumático asociados al acoso.

El objetivo de este estudio se centra en examinar la estructura factorial de las dos escalas de conductas de acoso del CAI, esto es la CAI-CA (CAI-Conductas de Acoso) y CAI-CAG (Conductas de Acoso asociadas al Género; Ítems 45-54 de la CAI-CA). De acuerdo con 
Tabla 1. Escalas y subescalas del Cuestionario de Acoso entre Iguales (CAI)

\begin{tabular}{|c|c|c|c|}
\hline Escala & Subescala & $\begin{array}{l}\text { Número } \\
\text { de items }\end{array}$ & Ítem representativo \\
\hline \multirow{7}{*}{$\begin{array}{l}\text { Conductas de Acoso } \\
\text { (CAI-CA) }\end{array}$} & Maltrato verbal & 11 & "Me insultan" \\
\hline & Exclusión social directa & 5 & "Me ocultan a donde van" \\
\hline & Amenazas & 4 & $\begin{array}{l}\text { "Me hacen gestos para meterse conmigo o } \\
\text { asustarme" }\end{array}$ \\
\hline & Ciberbullying & 4 & $\begin{array}{l}\text { "Me envían mensajes de móvil o correos } \\
\text { electrónicos para insultarme o amenazarme" }\end{array}$ \\
\hline & Exclusión social indirecta & 4 & "Les prohíben a otros que jueguen conmigo" \\
\hline & Agresión basada en objetos & 3 & $\begin{array}{l}\text { "Me tiran cosas (objetos de clase, pelotas de } \\
\text { papel, piedras, etc.)" }\end{array}$ \\
\hline & Maltrato físico & 8 & "Me tiran del pelo" \\
\hline \multirow{3}{*}{$\begin{array}{l}\text { Conductas de Acoso } \\
\text { de Género (CAI-CAG) }\end{array}$} & Chicos & 5 & "Me llaman nenaza" \\
\hline & Inconformismo de género & 3 & $\begin{array}{l}\text { "Se meten conmigo porque me gustan cosas } \\
\text { de chicos" }\end{array}$ \\
\hline & Atractivo físico & 2 & "Dicen a otros que soy fea" \\
\hline \multirow[t]{3}{*}{ Escenarios (CAI-E) } & Escenarios situados fuera del recinto escolar & 4 & "Andando, de camino a casa " \\
\hline & Escenarios no vigilados dentro del recinto escolar & 4 & "En los pasillos" \\
\hline & Escenarios vigilados dentro del recinto escolar & 6 & "En el patio cuando vigila algún profesor/a" \\
\hline \multirow[t]{3}{*}{ Personajes (CAI-P) } & Defensores y observadores & 3 & $\begin{array}{l}\text { "¿Hay compañeros que se quedan mirando } \\
\text { sin hacer nada?" }\end{array}$ \\
\hline & Agresores de distintos cursos que la víctima & 4 & "Chicos de cursos superiores al mío" \\
\hline & Agresores del mismo curso que la víctima & 2 & "Chicos de mi misma clase" \\
\hline \multirow[t]{2}{*}{ Afrontamiento (CAI-A) } & Autofocalización negativa & 4 & $\begin{array}{l}\text { "Nada, porque creo que esta situación nunca } \\
\text { se va a solucionar" }\end{array}$ \\
\hline & Focalización en el problema & 3 & $\begin{array}{l}\text { "Respondo de la misma forma que ellos, } \\
\text { cuando se meten conmigo" }\end{array}$ \\
\hline Confidentes (CAI-C) & & 6 & Padres, amigos, compañeros, etc. \\
\hline $\begin{array}{l}\text { Estrés Postraumático } \\
\text { (CAI-EP) }\end{array}$ & & 11 & $\begin{array}{l}\text { ¿Has soñado o tienes pesadillas donde ves } \\
\text { que tus compañeros se meten contigo, te pe- } \\
\text { gan, te insultan, no te hacen caso, etc.?” }\end{array}$ \\
\hline
\end{tabular}

este objetivo planteamos las siguientes hipótesis: (1) las conductas de acoso deberían agruparse mediante análisis factorial exploratorio en dimensiones correspondientes a tipos de acoso escolar establecidos y validados en la investigación previa, debiendo incluir al menos factores relativos a conductas de maltrato físico, maltrato verbal, exclusión social, amenazas y ciberbullying; (2) esperamos que la estructura factorial de la CAI-CA sea revalidada a través de la aplicación de análisis factoriales confirmatorios; y (3) las escalas CAI-CA y CAI-CAG deberían poseer adecuadas propiedades psicométricas en lo que concierne a su fiabilidad (estructura interna) y validez (validez convergente y discriminante). Respecto a la estructura de la CAI-CAG hipotetizamos una estructu- ra unidimensional representativa del acoso asociado a diferencias de género.

\section{Método}

\section{Participantes}

Participaron en el estudio 1.602 niños y adolescentes de Educación Primaria y Secundaria, pertenecientes a 12 centros educativos de la Comunidad de Madrid. El número de participantes masculinos fue de 836 (52.2\%), y el de participantes femeninos fue de 766 (47.8\%). La edad media de la muestra total era de 12.02 años $(D T=$ 1.42), la del grupo de chicos de 12.10 años $(D T=1.42)$, 
y la del grupo de chicas de 11.94 años $(D T=1.38)$. El rango de edad para la muestra total fue de 9-16 años, y correspondía a niños de primaria (9-12 años) y de secundaria (13-16 años). Por otra parte, también participó una muestra de 34 profesores-tutores de los niños/adolescentes, de los cuales 23 eran mujeres y 9 varones.

\section{Procedimiento}

Los cuestionarios fueron aplicados por el primer autor, de forma colectiva, por cursos escolares en las aulas de los propios centros de enseñanza en que se encontraban los alumnos. La aplicación de los cuestionarios se llevó a cabo tras la preceptiva autorización de los centros de enseñanza y el consentimiento informado de los padres. Paralelamente a la aplicación en el aula, se entregaba al profesor-tutor del curso el Cuestionario del Profesor. Todos los participantes completaron de forma voluntaria los cuestionarios.

\section{Instrumentos de evaluación}

Cuestionario de Acoso entre Iguales (CAI; Magaz et al., 2011). Para la presente investigación se consideraron las escalas de Conductas de Acoso (CAI-CA) y Conductas de Acoso de Género (CAI-CAG) del Cuestionario de Acoso entre Iguales (CAI) (véase la Tabla 1 y el Anexo I). La CAI-CA consta de 39 ítems comunes a chicos y chicas, los cuales hacen referencia a distintas conductas de acoso que los niños pueden sufrir por parte de otros chicos/as. A partir de esta escala pueden evaluarse de forma separada las siguientes formas de acoso entre iguales (subescalas): (1) maltrato verbal (11 ítems), (2) exclusión social directa (5 ítems), (3) amenazas (4 ítems), (4) ciberbullying (4 ítems), (5) exclusión social indirecta (4 ítems), (6) agresión basada en objetos (3 ítems), y (7) maltrato físico (8 ítems). La CAI-CAG está formada por 10 ítems, 5 para chicos y 5 para chicas. El contenido de los ítems específicos para los chicos hace referencia a ser objeto de maltrato verbal por falta de atractivo físico o interesarse por actividades o cosas de chicas (p.ej., "hablar de ropa"). En el caso de las chicas, el contenido de los ítems se corresponde con ser objeto de maltrato verbal por falta de atractivo físico o tener un interés elevado por estereotipos de actividades del otro sexo (p.ej., jugar al fútbol). Ambas escalas son contestadas por el participante según una escala de frecuencia de tres puntos que varía entre 1 («Nunca») y 3 («Muchas veces»). La construcción del cuestionario se llevó a cabo a partir de una revisión de la literatura sobre las conductas y aspectos relacionados con el bullying como victimización (Magaz, 2012). Los ítems de la escala de sínto- mas del trastorno de estrés postraumático se elaboraron sobre la base de la entrevista para el diagnóstico de los trastornos de ansiedad (Sandín, 2003; Silverman, Albano y Sandín, 2003a,b). Los ítems de la escala de afrontamiento se establecieron partiendo del cuestionario de afrontamiento del estrés de Sandín y Chorot (2003).

\section{Cuestionario del Profesor (CP)}

El Cuestionario del Profesor (CP) se elaboró ad-hoc para el presente estudio. En este cuestionario se presenta a los profesores una definición del acoso entre iguales, donde se especifican los tres criterios que deben estar presentes en toda conducta de agresión para que pueda ser considerada como acoso; estos son: (a) conducta agresiva dirigida a "hacer daño" intencionadamente, (b) realizada de forma repetida en el tiempo, incluso fuera del horario escolar, y (c) producida en el seno de una relación interpersonal caracterizada por un desequilibrio de poder o fuerza. A continuación, se les pedía que indicaran, en base a dichos criterios, si tenían conocimiento de que alguno de los alumnos del curso, del cual era tutor, había sufrido maltrato físico (MF; pegar, empujar, romperle o esconderle cosas, etc.), maltrato verbal (MV; insultar, poner motes, hablar mal de él, etc.), o exclusión social (ES; ignorarle, no dejarle participar en alguna actividad, etc.). En caso afirmativo, el profesor debía indicar mediante un número de identificación qué alumno o alumnos habían sido víctimas de acoso, señalando si se trataba de maltrato físico, maltrato verbal o social.

\section{Tratamiento estadístico de los datos}

Se efectuaron análisis factoriales exploratorios aplicando el método de extracción de ejes principales para la escala CAI-CA, y los métodos de componentes principales y ejes principales para la CAI-CAG. Para estimar el número de componentes a retener en los análisis factoriales se utilizaron criterios empíricos y teóricos. En concreto, aplicamos los siguientes criterios: (a) el test de scree (sedimentación) de Catell (1966), basado en la representación gráfica de los autovalores; (b) los criterios de Thurstone (1947) (número mínimo de "elementos complejos", número mínimo de "elementos hiperplanos", y adecuada definición de cada factor, i.e., que contenga tres o más pesos relevantes); y (c) el criterio de interpretabilidad de Gorsuch (1983), que implica examinar las soluciones factoriales con diferente número de componentes para determinar el punto en el que se inician los factores triviales. Utilizamos criterios teóricos basados en la evidencia de la literatura sobre los tipos de 
conductas de acoso escolar previamente establecidos. La rotación de los factores se llevó a cabo siguiendo métodos de rotación oblicua (método oblimin), la cual permite que los factores puedan correlacionar entre sí.

También aplicamos análisis factoriales confirmatorios con objeto de verificar empíricamente cuál o cuáles eran los mejores modelos sobre la estructura de las conductas de acoso. Para ello utilizamos el programa de ecuaciones estructurales EQS (Bentler, 1995). Para la elaboración de los modelos a confirmar nos basamos en los resultados obtenidos a partir de nuestros análisis factoriales exploratorios. Las estimaciones se efectuaron a partir de las matrices de covarianzas de la muestra. Las varianzas de las variables latentes se establecieron en 1.0 con objeto de fijar la escala de las variables no medidas e identificar el modelo (Bentler, 1995). En los diferentes modelos examinados partimos de que cada elemento constituía una variable de medida perteneciente a un solo factor (cada variable no era asignada a más de un factor), por lo cual las diferentes variables de medida se estimaron libremente para el factor relevante, y se fijaron en cero para los restantes factores. Las varianzas de los términos de error se estimaron libremente y no se permitió la correlación entre los valores residuales, lo cual confiere un mayor grado de exigencia a los modelos examinados. Aplicamos el método de estimación de máxima verosimilitud (ML) robusto (Bentler, 1995), con objeto de corregir posibles problemas relacionados con la distribución normal de los datos. Este método proporciona estadísticos robustos para los errores estándar y tests de significación, así como también para el $\chi^{2}$ (emplea la prueba escalada de $\chi^{2}$ Satorra-Bentler), corrigiendo los efectos debidos a una posible violación del principio de normalidad (por ejemplo, debido a que los datos obtenidos a partir de escalas tipo Likert no son datos continuos). Las estimaciones paramétricas de las ecuaciones de medida se calcularon en forma de coeficientes "completamente estandarizados"; este procedimiento estandariza, no solo las variables medidas, sino también sus residuos y los de las variables latentes, lo cual permite que los coeficientes sean más fácilmente interpretables.

Con objeto de contrastar la validez del modelo y comparar entre modelos rivales, se calcularon los siguientes índices de bondad de ajuste: (a) Coeficiente de $\chi^{2}$ dividido por los grados de libertad $\left(\chi^{2} / \mathrm{gl}\right)$; este índice es preferible al simple $\chi^{2}$, ya que este último se incrementa excesivamente y resulta significativo al aumentar el tamaño de la muestra; para muestras como la empleada en el presente estudio, el cociente no debería ser superior a 4.00; cuanto más bajo sea su valor mejor ajuste. (b) CFI robusto (comparative fit index); el valor de este índice debería acercarse a 0.90 para un buen ajuste (cuanto mayor sea el valor mejor es el ajuste). (c) Root mean square residual (SRMR); su valor no debería ser superior a 0.08 (a menor valor mejor ajuste). (d) Root mean square error of approximation (RMSEA); su valor no debería ser superior a 0.06 (a menor valor mejor ajuste). (e) Akaike's information criterion (AIC); éste es un índice relativo, y resulta de gran utilidad para decidir entre modelos competidores (el mejor modelo es el que posea el AIC de valor más bajo) (Sandín, Chorot, Valiente y Chorpita, 2010; Sandín et al., 2013).

Los análisis de fiabilidad incluyeron el cálculo de los coeficientes alfa de Cronbach y las correlaciones corregidas ítem-total e ítem-subescala. Los coeficientes alfa se calcularon tanto para las escalas totales como para las diferentes dimensiones o subescalas. Las correlaciones ítem-subescala se computaron para obtener información complementaria sobre la consistencia interna de las dimensiones (subescalas) obtenidas a partir de los análisis factoriales exploratorios.

Con objeto de proporcionar información sobre la validez convergente y discriminante de la CAI-CA, calculamos el coeficiente de correlación de Pearson entre las subescalas de la CAI-CA y el Cuestionario del Profesor de forma separada para los sujetos participantes en función de la edad (grupo docente) y el sexo.

\section{Resultados}

\section{Análisis factorial exploratorio del CAI-CA: Conductas comunes a ambos géneros}

Como primer paso se efectuó un análisis factorial en el que se incluyeron los 44 ítems originales de la CAICA. El análisis factorial sugirió 7 factores que explicaban el $48.1 \%$ de la varianza total. Sin embargo, 5 ítems presentaban saturaciones problemáticas, bien por saturar en varios factores, o por presentar saturaciones poco significativas. Estos ítems eran los siguientes: "Se ríen de mí a mis espaldas", "Se ríen de mí delante de mis compañeros", "Van contando mentiras de mí", "Cuentan mentiras de mí" y "Lo que yo digo no vale". Por tanto, estos ítems fueron eliminados en los sucesivos análisis y fueron suprimidos de la CAI-CA definitiva.

Tras aplicar los criterios de extracción indicados en el apartado de tratamiento estadístico de los datos, el análisis factorial aplicado a la forma definitiva de la CAI-CA (39 ítems) reflejaba la presencia de 7 factores interpretables, que explicaban el $48.4 \%$ de la varianza total. Los autovalores o valores propios iguales o superiores a 1.0 fueron los siguientes: $10.8 ; 1.9 ; 1.7 ; 1.3 ; 1.2$; $1.1 ; 1.1 ; 1.0 ; 1.0 ; 1.0$. Tras efectuarse la rotación oblimin 
para los primeros 7 factores, se obtuvieron las saturaciones factoriales que exponemos en la Tabla 2.

En la Tabla 2 se indica la presencia de siete factores para la muestra total. El primer factor (Factor 1) está configurado por 11 ítems $(22,16,12,18,11,5,37,15$, 20,19 , y 9) y lo denominamos Maltrato verbal, ya que las saturaciones relevantes en este factor $(\geq 0.30)$ corresponden a los ítems del CAI-CA que describen conductas que utiliza el agresor para hacer daño a la víctima usando el lenguaje verbal o gestual, de forma directa o indirecta ("Se ríen de mí cuando me equivoco", "Me acusan de cosas que no he dicho o hecho", "Me gritan", etc.)". El ítem 37 ("Hacen cosas para molestarme"), a nivel teórico (racional) también se puede considerar como una forma de maltrato físico (indirecto) aunque la confrontación entre agresor y víctima es menos violenta que aquellas conductas que se especifican en los ítems de maltrato físico (acciones físicas más directas). El Factor 1 explica el $27.6 \%$ de la varianza total.

El segundo factor (Factor 2) está definido por 5 ítems $(34,36,31,6$, y 23) y lo denominamos Exclusión social directa. Estos ítems se refieren a situaciones donde el tipo de conductas que utiliza el agresor para hacer daño a la víctima es ignorar, excluir y aislar a la víctima directamente, cara a cara ("No se quieren sentar conmigo", "Me impiden jugar con ellos", etc.). Este factor explica el $4.8 \%$ de la varianza total.

El Factor 3 está formado por cuatro ítems (39, 33, 38, y 35$)$ y lo hemos denominado Amenazas. En los ítems no se especifica una agresión, pero el agresor intimida a la víctima con el anuncio de la provocación de un mal grave, probablemente maltrato físico y/o verbal y exclusión social, si se niega a sus exigencias (p.ej.. "Me hacen gestos para meterse conmigo o asustarme"). Este factor explica el $4.3 \%$ de la varianza.

El cuarto factor (Factor 4), que denominamos Ciberbullying, está definido por 4 ítems $(29,27,28$ y 30). La agresión se produce a través de medios informáticos, y más específicamente a través de teléfonos móviles y de internet (p.ej., "Me hacen fotos o me graban con el móvil mientras se meten conmigo"). Este factor explica el $3.2 \%$ de la varianza total.

El Factor 5 lo denominamos Exclusión social indirecta y estaba configurado por elevadas saturaciones de los ítems 17, 21 y 14, y en menor medida por el ítem 8. Estos ítems se refieren a situaciones donde el agresor utiliza las relaciones sociales para aislar o excluir a la víctima (p.ej., "Les prohíben a otros que jueguen conmigo"). Este factor explica el 3\% de la varianza total.

El Factor 6 está formado por 3 ítems $(4,10$ y 32) y lo denominamos Agresión basada en objetos, ya que los ítems que lo forman hacen referencia a situaciones don- de el agresor ataca o amenaza a la víctima a través de objetos; no existe un contacto directo entre víctima y agresor (p.ej., "Me pegan con objetos)". Este factor explica el $2.8 \%$ de la varianza.

Finalmente, el Factor 7 está definido por 8 ítems (2, $3,1,26,24,13,25$ y 7) y fue denominado Maltrato físi$c o$, ya que los ítems que lo conforman hacen referencia a conductas mediante las cuales el agresor ataca a la víctima usando el cuerpo, y hay una confrontación abierta con la víctima (p.ej., "Me pegan puñetazos", "Me pegan patadas"). El porcentaje de varianza explicada por este factor fue del $2.7 \%$.

Las correlaciones entre los factores fueron bajas en general (oscilaron entre .42 y .09). La mayor parte de las correlaciones fueren inferiores a .20, y sólo cuatro fueron superiores a .30. La correlación más elevada $(r=0.42)$ se dio entre los factores maltrato verbal y maltrato físico. La correlación más baja $(r=0.09)$ se dio entre los factores agresión basada en objetos y exclusión social indirecta.

\section{Análisis factorial confirmatorio}

Con objeto de contrastar empíricamente la validez de la estructura factorial del CAI-CA que hemos aislado mediante análisis factorial exploratorio aplicado a la muestra total, efectuamos varios análisis factoriales confirmatorios sobre la matriz de covarianza de las puntuaciones en la muestras de chicos y chicas, consideradas ahora de modo separado. Mediante dichos análisis confirmatorios pretendíamos probar la bondad de ajuste del modelo de siete factores (correlacionado $v s$. no correlacionado), así como también contrastarlo con el modelo basado en un único factor, de forma separada según ambos grupos de género. Mediante el modelo de un solo factor queríamos probar que los datos no se ajustan mejor a un factor general de maltrato. De este modo sometimos a validación empírica confirmatoria los siguientes seis modelos sobre la estructura de las conductas de acoso, tres para el grupo de chicos y tres para el de chicas: (1) Modelo 1: Un único factor para el grupo de varones, (2) Modelo 2: Siete factores ortogonales para el grupo de varones, (3) Modelo 3: Siete factores correlacionados para el grupo de varones, (4) Modelo 4: Un único factor para el grupo de mujeres, (5) Modelo 5: Siete factores ortogonales para el grupo de mujeres, y (6) Modelo 6: Siete factores correlacionados para el grupo de mujeres. El hecho de incluir el modelo de un único factor se debe a que las conductas de maltrato entre iguales parecen estar altamente interrelacionadas, tal y como se deriva del elevado coeficiente alfa obtenido para la totalidad de los ítems del CAI-CA $(\alpha=0.93)$. En consecuencia, aunque los análisis exploratorios sugerían la existencia de varias 
Tabla 2. Análisis factorial de ejes principales de la CAI-CA.

Pesos factoriales tras rotación oblicua (oblimin) y correlaciones ítem-total e ítem-subescala corregidas. $(N=1.602)$

\begin{tabular}{|c|c|c|c|}
\hline Ítems de la CAI-CA $(\alpha=0.93)$ & Peso factorial & $r$ item-total & $r$ ítem-subescala \\
\hline \multicolumn{4}{|l|}{ Factor 1. Maltrato verbal $(\alpha=0.83)$} \\
\hline 22. Se ríen de mí cuando me equivoco & 0.60 & 0.51 & 0.53 \\
\hline 16. Me esconden cosas & 0.59 & 0.50 & 0.50 \\
\hline 12. Me acusan de cosas que no he dicho o hecho & 0.56 & 0.54 & 0.54 \\
\hline 18. Me gritan & 0.54 & 0.59 & 0.59 \\
\hline 11. Me mandan callar & 0.52 & 0.55 & 0.55 \\
\hline 5. Me insultan 7 & 0.49 & 0.66 & 0.66 \\
\hline 37. Hacen cosas para molestarme & 0.46 & 0.62 & 0.58 \\
\hline 15. Me dicen que se van a «chivar de mí» & 0.44 & 0.51 & 0.49 \\
\hline 20. Me roban cosas & 0.31 & 0.47 & 0.43 \\
\hline 19. Me rompen cosas & 0.26 & 0.46 & 0.41 \\
\hline 9. Me llaman con un nombre que no me gusta ${ }^{2}$ & 0.25 & 0.51 & 0.47 \\
\hline \multicolumn{4}{|l|}{ Factor 2. Exclusión social directa $(\alpha=0.77)$} \\
\hline 34. No quieren hacer trabajos conmigo & 0.67 & 0.52 & 0.61 \\
\hline 36. No se quieren sentar conmigo & 0.66 & 0.52 & 0.60 \\
\hline 31. Me mienten para que no vaya con ellos & 0.48 & 0.57 & 0.55 \\
\hline 6. Me impiden jugar con ellos & 0.44 & 0.50 & 0.47 \\
\hline 23. Me ocultan a dónde van & 0.38 & 0.50 & 0.49 \\
\hline \multicolumn{4}{|l|}{ Factor 3. Amenazas $(\alpha=0.70)$} \\
\hline 39. Me amenazan para que haga cosas que no quiero & 0.72 & 0.42 & 0.48 \\
\hline 33. Me amenazan para que diga cosas que no quiero & 0.67 & 0.52 & 0.57 \\
\hline 38. Me hacen gestos para meterse conmigo o asustarme & 0.48 & 0.58 & 0.47 \\
\hline 35. Me amenazan con contar cosas de mí o de mi familia & 0.48 & 0.49 & 0.48 \\
\hline \multicolumn{4}{|l|}{ Factor 4. Ciberbullying $(\alpha=0.45)$} \\
\hline 29. Me hacen fotos o me graban con el móvil mientras se meten conmigo & 0.70 & 0.18 & 0.26 \\
\hline 27. Me envían mensajes de móvil o correos electrónicos para insultarme & 0.69 & 0.25 & 0.35 \\
\hline 28. Cuando chateo con otros niños. se meten conmigo & 0.50 & 0.38 & 0.31 \\
\hline 30. Se burlan colgando fotos o vídeos sobre mí en internet ${ }^{2,5}$ & 0.46 & 0.19 & 0.22 \\
\hline \multicolumn{4}{|l|}{ Factor 5. Exclusión social indirecta $(\alpha=0.58)$} \\
\hline 17. Les prohíben a otros que jueguen conmigo & 0.71 & 0.44 & 0.47 \\
\hline 21. Me impiden jugar con otros niños ${ }^{3}$ & 0.57 & 0.43 & 0.38 \\
\hline 14. Les dicen a otros que no estén o que no hablen conmigo ${ }^{2}$ & 0.44 & 0.57 & 0.46 \\
\hline 8. Me dejan de hablar & 0.28 & 0.32 & 0.29 \\
\hline \multicolumn{4}{|l|}{ Factor 6. Agresión basada en objetos $(\alpha=0.56)$} \\
\hline 4. Me pegan con objetos & 0.74 & 0.38 & 0.47 \\
\hline 10. Me amenazan con objetos & 0.58 & 0.45 & 0.40 \\
\hline 32. Me tiran $\operatorname{cosas}^{1}$ & 0.39 & 0.46 & 0.36 \\
\hline \multicolumn{4}{|l|}{ Factor 7. Maltrato físico $(\alpha=0.79)$} \\
\hline 2. Me pegan puñetazos & 0.74 & 0.43 & 0.47 \\
\hline 3. Me pegan patadas & 0.73 & 0.56 & 0.60 \\
\hline 1. Me pegan collejas & 0.55 & 0.51 & 0.51 \\
\hline 26. Me tiran del pelo & 0.43 & 0.45 & 0.44 \\
\hline 24. Me ponen la zancadilla & 0.39 & 0.49 & 0.50 \\
\hline 13. Me empujan ${ }^{1}$ & 0.39 & 0.63 & 0.60 \\
\hline 25. Me pellizcan ${ }^{1}$ & 0.32 & 0.44 & 0.45 \\
\hline 7. Me amenazan que van a pegarme & 0.29 & 0.57 & 0.47 \\
\hline
\end{tabular}

Nota. Los superíndices numéricos indican que el ítem también saturó $(\geq 0.30)$ en el número de factor que corresponda al número del superíndice. 
dimensiones factoriales, parecía necesario llevar a cabo esta contrastación. No hemos incluido otros modelos estructurales (p.ej., modelo de cuatro, cinco o seis factores) puesto que nuestros análisis factoriales exploratorios descartaban claramente estas opciones.

Los resultados indicaron que para el grupo de chicos el modelo que mejor se ajustaba era el modelo de siete factores no correlacionados, constatándose los siguientes valores para los distintos índices de bondad de ajuste: $S-B \chi^{2}=421.4(663), S-B \chi^{2} /$ g.l. $=0.63, C F I=0.99$, $\mathrm{SRMR}=0.06, \mathrm{y}$ RMSEA $=0.01, \mathrm{AIC}=-904.6$. Para el grupo de chicas el modelo que mejor se ajustaba a los datos también fue el modelo de siete factores no correlacionado verificándose los siguientes valores para los distintos índices de bondad de ajuste: $S-B \chi^{2}=4.943$ (663), $S$ - $B \chi^{2} /$ g.l. $=0.01, \mathrm{CFI}=0.99, \mathrm{SRMR}=0.06, \mathrm{y}$ RMSEA $=0.01, \mathrm{AIC}=-1321.1$

Se observa, en general, que los resultados, tanto los parámetros estimados como los índices de ajuste calculados mejoran considerablemente en los modelos de siete factores. Asimismo, comparando los índices de ajuste de los modelos de siete factores entre los grupos de chicas y chicos, se obtienen mejores niveles de ajuste para el modelo de siete factores no correlacionados en ambos grupos (considerados de forma independiente). Por tanto, podríamos decir que la estructura factorial de las conductas de acoso, que se evidencia en una muestra general de niños y adolescentes, permanece estable a través del género, y consiste en siete factores relativamente independientes. Las estimaciones paramétricas para las variables correspondientes a este modelo se indican en la Tabla 3.

\section{Análisis factorial exploratorio de la CAI-CAG: Conductas especificas de género}

Se aplicaron análisis separados para los cinco ítems referidos a los chicos y los cinco ítems referidos a las chicas. También realizamos análisis factoriales de forma separada para los grupos de primaria y secundaria

Los 5 ítems del grupo de chicos fueron factorizados mediante los métodos de análisis de componentes principales y ejes principales (véase la Tabla 4). En ambos casos se obtenía una estructura factorial de un único factor. Basándonos en los resultados obtenidos con el método de componentes principales, el único factor explicaba el $50.9 \%$ de la varianza total, siendo el tamaño de los autovalores como sigue: $2.6,0.9,0.6,0.5,0.5$, respectivamente para cada uno de los 5 ítems. Siguiendo el método de ejes principales, el único factor extraído explicaba el $38,8 \%$ de la varianza total, siendo el tamaño de los autovalores para cada uno de los 5 ítems idénticos a los obtenidos con el método de componentes principales.
Para el grupo de chicas, los 5 ítems también fueron factorizados mediante ambos métodos (véase la Tabla 4). En los dos casos obtuvimos una estructura factorial bastante consistente de 2 factores. Basándonos en los resultados obtenidos con el método de componentes principales, los dos factores explicaban el $65.5 \%$ de la varianza total, siendo el tamaño de los autovalores el siguiente: $2.1,1.2,0.9,0.5,0.5$. Según el método ejes principales, los factores explicaban el $45.8 \%$ de la varianza total, siendo el tamaño de los autovalores muy similares a los obtenidos por el método de componentes principales. En la Tabla 4 indicamos los pesos factoriales obtenidos para ambos métodos tras rotación oblicua. Como puede apreciarse en dicha tabla, el primer factor (Factor 1) está configurado por 3 ítems $(41,43$ y 40) y lo denominamos Inconformismo de género. El contenido de estos ítems hace referencia a situaciones donde las chicas expresan un interés alto por actividades masculinas ("Se meten conmigo porque me gustan cosas de chicos"), presentan un aspecto masculino ("Me llaman marimacho"), o prefieren estar con chicos ("Van diciendo que voy con muchos chicos"); es decir, no responden a la idea aceptada por la sociedad de lo que es "femenino" y de cómo deben actuar las mujeres. El segundo factor (Factor 2) está definido por dos ítems (44 y 42), y lo denominamos Atractivo físico, ya que en ellos queda reflejado que la belleza o atractivo físico es motivo de intimidación ("Dicen a otros que soy fea", y "Se meten conmigo porque no gusto a los chicos"). La correlación entre ambos factores fue moderada $(r=0.26)$.

Dada la discrepancia entre los resultados de los análisis factoriales obtenidos entre ambos grupos de sujetos (i.e., chicos vs. chicas), diferencias que se mantienen con independencia del método de extracción factorial utilizado, aplicamos, siguiendo el método de componentes principales, nuevos análisis factoriales separando entre los grupos de edad (primaria vs. secundaria), con objeto de ver si las estructuras factoriales (unifactorial en los chicos y bifactorial en las chicas) se mantenía con independencia de la edad. Los resultados de estos análisis se indican en la Tabla 5, y sugieren que la estructura unifactorial sólo aparece asociada a los chicos y al grupo de mayor edad (adolescentes).

En lo que concierne a los resultados referidos a los chicos, en el grupo de primaria obtuvimos una estructura bifactorial similar conceptualmente a la obtenida con el grupo de niñas/adolescentes. El primer factor (Factor 1) está definido por tres ítems $(45,47$, y 49$)$, y se corresponde con el factor que denominamos Atractivo físico obtenido en el grupo de chicas. Este factor explica el 46.4\% de la varianza total. El segundo factor (Factor 2) está conformado por los ítems 46 y 48, y se corresponde con el denominado como Inconformismo de género en el grupo 
Tabla 3. Análisis factorial confirmatorio del modelo de 39 ítems de la escala CAI-CA.

Se indican las estimaciones paramétricas estandarizadas en función de los grupos de género (chicos vs. chicas)

\section{Factor 1. Maltrato verbal}

Chicos $(n=836)$

Chicas $(n=766)$

5. Me insultan

9. Me llaman con un nombre que no me gusta

0.73

0.54

0.63

0.62

0.54

0.54

0.64

0.44

0.45

0.60

0.64

37. Hacen cosas para molestarme

\section{Factor 2. Exclusión social directa}

6. Me impiden jugar con ellos

\subsection{0}

0.57

0.60

0.72

0.70

36. No se quieren sentar conmigo

\section{Factor 3. Amenazas}

33.Me amenazan para que diga cosas que no quiero

0.75

0.54

0.57

0.63

0.70

35.Me amenazan con contar cosas de mí o de mi familia

38. Me hacen gestos para meterse conmigo o asustarme

39. Me amenazan para que haga cosas que no quiero

\section{Factor 4. Ciberbullying}

27. Me envían mensajes de móvil o correos electrónicos para insultarme

28. Cuando chateo con otros niños, se meten conmigo

29. Me hacen fotos o me graban con el móvil mientras se meten conmigo

30. Se burlan colgando fotos o vídeos sobre mí en internet

\section{Factor 5. Exclusión social indirecta}

8. Me dejan de hablar

17. Les prohíben a otros que jueguen conmigo

14. Les dicen a otros que no estén o que no hablen conmigo

21. Me impiden jugar con otros niños

\section{Factor 6. Agresión basada en objetos}

4. Me pegan con objetos

10. Me amenazan con objetos

32. Me tiran cosas

\section{Factor 7. Maltrato físico}

1. Me pegan collejas

2. Me pegan puñetazos

0.34

0.34

0.75

0.87

0.61

0.54

0.69

0.54

3. Me pegan patadas

0.70

0.85

0.61

0.38

7. Me amenazan con que me pegan

0.60

0.54

13.. Me empujan

0.72

0.43

0.60

0.63

24. Me ponen la zancadilla

0.66

0.46

0.62

0.72

25. Me pellizcan

0.50

0.49

26. Me tiran del pelo 
Tabla 4 Análisis factorial de componentes principales (CPA) y ejes principales (EP) de los ítems del CAI referidos al género (CAI-CAG) en el grupo de chicos $(n=836)$ y de chicas $(n=766)$. Pesos factoriales tras rotación oblicua (oblimin)

\begin{tabular}{|c|c|c|c|c|}
\hline \multirow[t]{2}{*}{ CAI-CAG (chicos) $(\alpha=0.75)$} & PCA & $\mathrm{EP}$ & & \\
\hline & F1 & F1 & & \\
\hline 45. Van diciendo que no voy con chicas & 0.67 & 0.56 & & \\
\hline 46. Me llaman "nenaza" & 0.72 & 0.61 & & \\
\hline 47. Se meten conmigo porque no gusto a las chicas & 0.76 & 0.68 & & \\
\hline 48. Se meten conmigo porque me gustan cosas de chicas & 0.71 & 0.61 & & \\
\hline 49. Dicen a otros que soy feo & 0.74 & 0.66 & & \\
\hline \multirow[t]{2}{*}{ CAI-CAG (chicas) $(\alpha=0.63)$} & \multicolumn{2}{|c|}{ PCA } & \multicolumn{2}{|c|}{ EP } \\
\hline & F1 & $\mathrm{F} 2$ & F1 & $\mathrm{F} 2$ \\
\hline \multicolumn{5}{|l|}{ Factor 1. Inconformismo de género $(\alpha=0.56)$} \\
\hline 41. Me llaman marimacho & 0.92 & 0.20 & 0.89 & 0.15 \\
\hline 43. Se meten conmigo porque me gustan cosas de chicos & 0.76 & 0.18 & 0.64 & 0.30 \\
\hline 40. Van diciendo que voy con muchos chicos & 0.51 & 0.06 & 0.27 & 0.16 \\
\hline \multicolumn{5}{|l|}{ Factor 2. Atractivo físico $(\alpha=0.71)$} \\
\hline 44. Dicen a otros que soy fea & 0.02 & 0.87 & 0.29 & 0.75 \\
\hline 42. Se meten conmigo porque no gusto a los chicos & 0.01 & $\mathbf{0 . 8 8}$ & 0.31 & 0.73 \\
\hline$\%$ Varianza explicada & $41.6 \%$ & $23.9 \%$ & $30.9 \%$ & $14.9 \%$ \\
\hline
\end{tabular}

Nota: En negrita se indican los pesos factoriales asignados a las variables relevantes (asociadas) a cada factor.

de chicas. El contenido de estos ítems hace referencia a situaciones donde los chicos expresan un interés alto por actividades femeninas. Este factor explica el $21.7 \%$ de la varianza total (véase la Tabla 5). En la misma tabla podemos observar que para el grupo de secundaria se obtuvo un único factor, que explicaba el $55.6 \%$ de la varianza total. Por tanto, la estructura unifactorial sólo parece darse en el grupo de chicos adolescentes.

Para los ítems asociados al género femenino y a los grupos de chicas (primaria vs. secundaria), constatamos una estructura factorial de dos factores similar a la descrita para el grupo total de chicas. En ambos grupos docentes se mantiene una estructura factorial análoga, siendo también similar la varianza total explicada por los dos factores en ambos grupos docentes (65.5\% en el grupo de primaria y $64.1 \%$ en el grupo de secundaria).

\section{Fiabilidad de las escalas CAI-CA y CAI-CAG}

La consistencia interna (fiabilidad) de la CAI-CA indica un nivel elevado de fiabilidad de la escala total $(\alpha=$ 0.93). En lo que concierne a las diferentes subescalas, los coeficientes fueron buenos para las dimensiones de maltrato verbal, maltrato físico, exclusión social directa, y amenazas (rango 0.83-0.70). Para el resto de subescalas (ciberbullying, exclusión social indirecta, y agresión basada en objetos) la fiabilidad fue más limitada (rango de los coeficientes alfa $=0.45-0.58)$, lo cual se explica, al menos parcialmente, por el menor número de ítems (véase la Tabla 2). Los coeficientes alfa de la escala CAI-CAG, así como de las dos subescalas descritas para el grupo de chicas son aceptables (véase la Tabla 4).

Finalmente, también calculamos las correlaciones corregidas (suprimiendo el ítem) entre cada uno de los ítems y la puntuación total en la escala y subescala (a la que pertenece el ítem). Las correlaciones referidas a la CAI-CA se indican en la Tabla 2. En general las correlaciones indican una buena consistencia interna de la escala, y sugieren que el uso separado de cada subescala es adecuado (en muchos casos, las correlaciones son superiores con la subescala que con la escala total). Calculamos tipos similares de correlaciones con los ítems de la escala CAI-CAG, obteniendo resultados que apoyan la fiabilidad de esta escala y de las dos subescalas obtenidas en el grupo de chicas. Las correlaciones de cada ítem con la escala total (5 ítems) en el grupo de chicos variaron entre 0.48 y 0.59 . Las correlaciones de cada ítem con las subescalas de la CAI-CAG en el grupo de chicas en general se acercaron o superaron el valor de 0.50 .

\section{Validez convergente y discriminante}

Analizamos la validez de la CAI-CA y CAI-CAG mediante análisis de correlaciones entre estas escalas y 
Tabla 5.Análisis factorial de componentes principales de los ítems (CAI-CAG) referidos al género masculino y femenino para los grupos de primaria y secundaria. Pesos factoriales tras rotación oblicua (oblimin)

\begin{tabular}{|c|c|c|c|c|}
\hline \multirow[t]{2}{*}{ CAI-CAG (chicos) } & \multicolumn{2}{|c|}{$\begin{array}{l}\text { Primaria } \\
(n=357)\end{array}$} & \multirow{2}{*}{$\begin{array}{c}\begin{array}{c}\text { Secundaria } \\
(n=479)\end{array} \\
\text { F1 }\end{array}$} & \\
\hline & F1 & $\mathbf{F} 2$ & & \\
\hline 45. Van diciendo que no voy con chicas & 0.90 & 0.15 & 0.67 & \\
\hline 47. Se meten conmigo porque no gusto a las chicas & $\mathbf{0 . 8 3}$ & 0.03 & 0.79 & \\
\hline 49. Dicen a otros que soy feo & 0.58 & 0.30 & 0.75 & \\
\hline 46. Me llaman nenaza & 0.11 & 0.79 & 0.72 & \\
\hline 48. Se meten conmigo porque me gustan cosas de chicas & 0.10 & 0.90 & 0.80 & \\
\hline$\%$ Varianza explicada & 46.4 & 21.7 & 55.6 & \\
\hline \multirow[t]{2}{*}{ CAI-CAG (chicas) } & \multicolumn{2}{|c|}{$\begin{array}{c}\text { Primaria } \\
(n=359)\end{array}$} & \multicolumn{2}{|c|}{$\begin{array}{c}\text { Secundaria } \\
\quad(n=407)\end{array}$} \\
\hline & F1 & F2 & F1 & F2 \\
\hline \multicolumn{5}{|l|}{ Factor 1. Inconformismo de género } \\
\hline 41. Me llaman marimacho & 0.92 & 0.20 & 0.83 & 0.01 \\
\hline 43. Se meten conmigo porque me gustan cosas de chicos & 0.76 & 0.18 & 0.82 & 0.05 \\
\hline 40. Van diciendo que voy con muchos chicos & 0.52 & 0.07 & 0.50 & 0.04 \\
\hline \multicolumn{5}{|l|}{ Factor 2. Atractivo físico } \\
\hline 42. Se meten conmigo porque no gusto a los chicos & 0.01 & 0.88 & 0.07 & 0.86 \\
\hline 44. Dicen a otros que soy fea & 0.02 & 0.87 & 0.06 & 0.90 \\
\hline$\%$ Varianza explicada & 41.6 & 23.9 & 41.3 & 22.7 \\
\hline
\end{tabular}

Nota. En negrita se indican los pesos factoriales asignados a las variables relevantes (asociadas) a cada factor.

un criterio externo (puntuaciones del profesor-tutor) referido a las conductas de acoso sufridas por el alumno (físico, verbal, y exclusión social). En las Tabla 6 y 7 se indican las correlaciones entre las estimaciones del profesor y el autoinforme de los alumnos, en función del género (Tabla 6) y la edad de los alumnos (Tabla 7). Como puede apreciarse en dichas tablas, la percepción de maltrato verbal, exclusión social, y estimación global de acoso que tiene el profesor se relaciona de forma significativa con diferentes formas de maltrato autoinformado por los niños. Aunque en general el patrón de correlaciones resulta bastante similar para ambos grupos de género, y sugiere una relación significativa entre el acoso percibido por el niño y el acoso observado por el profesor, una diferencia notable consiste en que las estimaciones del profesor sobre el maltrato físico correlacionan con el maltrato físico percibido por los chicos, pero no con el maltrato físico percibido por las chicas.

Si comparamos las correlaciones en función de la edad (Tabla 7) podemos observar que en el grupo de primaria los profesores parecen tener una mayor percepción sobre el maltrato verbal, la exclusión social y el nivel general de maltrato que sobre el maltrato físico. En contraste en el grupo de secundaria el profesor parece percibir en menor grado el maltrato relacionado con la exclusión social. Al menos los análisis correlacionales sugieren esto de forma indirecta.

En términos generales se constata que las puntuaciones obtenidas en las escalas CAI-CA y CAI-CAG (percepción del grado de bullying experimentado por el niño) correlacionan, aunque de forma baja o moderada baja, con la percepción que tiene el profesor sobre el acoso sufrido por el niño. Estos datos proporcionan evidencia empírica parcial sobre la validez convergente y discriminante de dichas escalas (véanse las Tablas 6 y 7). En cualquier caso, dadas las características del bullying, no es esperable que se den correlaciones elevadas entre la percepción que tiene el niño de las conductas de acoso y lo que observa el profesor.

\section{Discusión}

El objetivo de este estudio consistió en validar el CAI, un nuevo instrumento de autoinforme para la evaluación del acoso entre iguales (bullying) desde el punto de vista de la victimización percibida (i.e., bullying per- 
Tabla 6. Coeficientes de correlación entre las escalas CAI-CA, CAI-CAG y las estimaciones del profesor (MF, MV, ES y Total) para los grupos de $\operatorname{chicos}(n=836)$ y de chicas $(n=766)$

\begin{tabular}{lllllllll}
\hline & \multicolumn{4}{c}{ Chicos } & \multicolumn{3}{c}{ Chicas } \\
\cline { 2 - 8 } CAI-CA & MF & MV & ES & Total & MF & MV & ES & Total \\
MV & $0.12^{* *}$ & $0.15^{* * *}$ & $0.09^{*}$ & $0.16^{* * *}$ & 0.042 & $0.11^{*}$ & $0.19^{* * *}$ & $0.18^{* * *}$ \\
ESD & $0.09^{*}$ & $0.16^{* * *}$ & $0.16^{* * *}$ & $0.19^{* * *}$ & -0.06 & $0.12^{* *}$ & $0.27^{* * *}$ & $0.22^{* * *}$ \\
AM & 0.02 & $0.13^{* *}$ & 0.08 & $0.12^{* *}$ & 0.036 & $0.13^{* *}$ & $0.16^{* * *}$ & $0.18^{* * *}$ \\
CB & $0.11^{* *}$ & 0.04 & $0.13^{* *}$ & $0.12^{* *}$ & 0.013 & -0.01 & -0.02 & -0.01 \\
ESI & $0.12^{* *}$ & $0.10^{*}$ & $0.08^{*}$ & $0.14^{* *}$ & 0.013 & 0.08 & $0.14^{* *}$ & $0.13^{* *}$ \\
ABO & $0.14^{* *}$ & 0.06 & 0.05 & $0.11^{*}$ & 0.027 & $0.16^{* * *}$ & $0.13^{* *}$ & $0.18^{* * *}$ \\
MF & $0.09^{*}$ & $0.12^{* *}$ & 0.08 & $0.14^{* *}$ & 0.006 & $0.11^{* *}$ & $0.19^{* * *}$ & $0.18^{* * *}$ \\
CAI-CA Total & $0.12^{* *}$ & $0.15^{* * *}$ & $0.12^{* *}$ & $0.18^{* * *}$ & 0.027 & $0.13^{* *}$ & $0.23^{* * *}$ & $0.22^{* * *}$ \\
CAI-CAG & -0.03 & 0.02 & 0.05 & 0.02 & $0.09 *$ & $0.14^{* *}$ & $0.11^{*}$ & $0.17^{* * *}$ \\
\hline
\end{tabular}

Nota $:$ ABO = Agresión basada en objetos; AM = Amenazas; CAI-CA = CAI-Conductas de acoso; CAI-CAG = Total de conductas de acoso de género; $\mathrm{CB}=$ Ciberbullying; $\mathrm{CP}=$ Cuestionario del profesor. $\mathrm{ES}=$ Exclusión social. ESD = Exclusión social directa; $\mathrm{ESI}=$ Exclusión social indirecta; $\mathrm{MF}=$ Maltrato físico; $\mathrm{MV}=$ Maltrato verbal; ${ }^{*} p<0,05 ; * * p<0,01 ; * * * p<0,001$.

cibido por la víctima). Este instrumento incluye varias escalas (véase la Tabla 1), dos de las cuales evalúan las conductas de acoso en general (CAI-CA) y las conductas de acoso asociadas al género (CAI-CAG). En el presente estudio examinamos la estructura factorial, la fiabilidad y la validez de estas dos escalas.

Los resultados de los análisis factoriales exploratorios y confirmatorios sugieren que la CAI-CA es una escala multifactorial que posibilita evaluar siete dimensiones del bullying percibido relacionadas con el maltrato verbal, el maltrato físico, la exclusión social directa, las amenazas, el ciberbullying, la exclusión social indirecta, y la agresión basada en objetos. Estas dimensiones fueron aisladas mediante análisis factorial de ejes principales aplicado a la muestra total de niños y adolescentes, y posteriormente fueron replicadas mediante análisis factorial confirmatorio aplicado a las muestras de chicos y chicas de forma separada, lo cual confirma que la estructura factorial de la CAI-CA, y sugiere que ésta se mantiene estable tanto en el grupo de chicos como en el de chicas.

Aunque la estructura factorial es en general bastante robusta, y sugiere la posibilidad de utilizar las siete subescalas para evaluar de forma separada diferentes tipos de bullying, la fiabilidad (consistencia interna) varía entre unas subescalas y otras. Ésta es excelente o buena para las subescalas de maltrato verbal, maltrato físico, exclusión social directa, y amenazas. Es cambio es más limitada para las subescalas de ciberbullying, exclusión social indirecta, y agresión basada en objetos, por lo que deben utilizarse con mayor cautela.
Entre las siete dimensiones de bullying aisladas, cinco (maltrato físico, maltrato verbal, exclusión social directa, exclusión social indirecta y amenazas coinciden conceptualmente, en términos generales, con dimensiones referidas en algunas clasificaciones sobre los tipos de acoso escolar propuestas por diferentes autores (Funk, 1997; Mynard y Josph, 1994; Olweus, 1996, 1998, 2002; Sullivan, Cleary y Sullivan, 2003). Otras dimensiones, en cambio, no habían sido propuestas por la literatura, tal como la dimensión de "agresión basada en objetos", es decir, situaciones donde el agresor ataca o amenaza a la víctima a través de objetos, no existiendo contacto directo entre víctima y agresor. La CAI-CA también incluye una dimensión sobre ciberbullying, una nueva forma de maltrato basado en el uso de las tecnologías de la información y la comunicación (sobre todo a través del uso de internet y el smartphone) que ha despertado un gran interés en los últimos años (Garaigordobil, 2014; Hansen et al., 2012; Slonge, 2011).

En relación con la CAI-CAG (conductas de bullying relacionadas con el rol de género), los análisis factoriales indican la presencia de dos dimensiones en el grupo de chicas, una relacionada con el inconformismo de género y la otra con el bajo atractivo físico. Esta estructura se mantuvo estable con independencia del grupo de edad de las chicas. En contraste, en el grupo de adolescentes sólo aislamos una dimensión general en la que se combinan ambos fenómenos (inconformismo de género y atractivo físico), aunque en el grupo de niños (primaria) la estructura fue bifactorial y similar a la obtenida con 
Tabla 7. Coeficientes de correlación entre las escalas CAI-CA, CAI-CAG y las estimaciones del profesor (MF, MV, ES y Total) para los grupos de primaria $(n=716)$ y de secundaria $(n=886)$

\begin{tabular}{lllllllcc}
\hline & \multicolumn{9}{c}{ Primaria } & \multicolumn{2}{c}{ Secundaria } \\
\cline { 2 - 8 } CAI-CA & MF & MV & ES & Total & MF & MV & ES & Total \\
MV & & & & & & & \\
ESD & 0.06 & $0.09^{*}$ & $0.14^{* *}$ & $0.14^{* *}$ & $0.11^{* *}$ & $0.17^{* * *}$ & $0.09^{*}$ & $0.18^{* * *}$ \\
AM & 0.04 & $0.10^{*}$ & $0.22^{* * *}$ & $0.18^{* * *}$ & 0.07 & $0.19^{* * *}$ & $0.12^{* *}$ & $0.19^{* * *}$ \\
CB & 0.04 & 0.09 & $0.10^{*}$ & $0.11^{*}$ & 0.01 & $0.21^{* * *}$ & 0.08 & $0.16^{* * *}$ \\
ESI & 0.02 & -0.03 & 0.03 & 0.01 & $0.10^{* *}$ & 0.06 & 0.05 & $0.10^{*}$ \\
ABO & $0.10^{*}$ & $0.11^{*}$ & $0.12^{* *}$ & $0.15^{* *}$ & 0.03 & 0.05 & 0.01 & 0.05 \\
MF & $0.10^{*}$ & 0.07 & $0.13^{* *}$ & $0.14^{* *}$ & $0.12^{* *}$ & $0.14^{* *}$ & 0.06 & $0.15^{* * *}$ \\
CAI-CA Total & 0.05 & $0.11^{*}$ & $0.13^{* *}$ & $0.14^{* *}$ & $0.10^{*}$ & $0.13^{* *}$ & 0.07 & $0.15^{* * *}$ \\
CAI-CAG & 0.06 & $0.11^{*}$ & $0.17^{* * *}$ & $0.17^{* * *}$ & $0.11^{* *}$ & $0.19^{* * *}$ & $0.10^{*}$ & $0.19^{* * *}$ \\
\hline
\end{tabular}

Nota $:$ ABO = Agresión basada en objetos; AM = Amenazas; CAI-CA = CAI-Conductas de acoso; CAI-CAG = Total de conductas de acoso de género; $\mathrm{CB}=$ Ciberbullying; $\mathrm{CP}=$ Cuestionario del profesor. ES = Exclusión social. ESD = Exclusión social directa; $\mathrm{ESI}=$ Exclusión social indirecta; $\mathrm{MF}=$ Maltrato físico; $\mathrm{MV}=$ Maltrato verbal; $* p<0,05 ; * * p<0,01 ; * * * p<0,001$.

los grupos de chicas. Estos resultados apoyan los perfiles establecidos por Shakeshaft et al. (1995), sobre el riesgo de sufrir acoso en relación con la variable género. Según estos autores, aquellas chicas que son vistas por sus iguales como poco atractivas, y los chicos cuyo comportamiento no se ajusta a los estereotipos de su género, tienen más probabilidades de sufrir acoso escolar que otros niños.

Aunque la fiabilidad de la escala CAI-CA resultó ser elevada ( $\alpha=0.93$ ), no todas las subescalas resultaron poseer niveles óptimos de consistencia interna. Algunas subescalas, incluida la escala de ciberbullying, exhibieron un nivel moderado de fiabilidad (basada en el nivel del coeficiente alfa), lo cual sugiere la necesidad de nuevos estudios sobre las mismas. Dado que el número de ítems de estas escalas es bajo, sin duda un incremento de componentes en estas dimensiones mejoraría su consistencia interna. No obstante, los resultados del análisis basado en las correlaciones entre los ítems y la escala (o subescala) indicaron niveles adecuados de fiabilidad.

Otro de los objetivos principales consistió en proporcionar evidencia sobre la validez convergente y discriminante de las escalas CAI-CA y CAI-CAG. Nuestros resultados ponen de relieve que el profesor tiene un conocimiento general sobre la conductas de acoso de las que son objeto los alumnos, que correlaciona (aunque no de forma elevada) con las diferentes dimensiones de maltrato y con la puntuación total de la CAI-CA y CAICAG autoinformada por los niños. Las estimaciones que realiza el profesor sobre maltrato físico son las que me- nos correlacionan con la percepción que tienen los niños sobre esta forma de acoso. En este sentido nuestros resultados no coincidirían con los presentados por otros autores (Boulton, 1997; Hazler, Miller, Carney y Green, 2001), los cuales señalaron que los profesores no tenían dificultad para identificar como maltrato las agresiones físicas, el chantaje o las amenazas, aunque tenían más problemas para detectar los casos de acoso más imprecisos representados por las formas de exclusión social, abusos verbales y socioemocionales. Nuestros resultados están más en la línea de los ofrecidos por Genta, Menesini, Fonzi, Costabile, y Smith, (1996), quienes resaltan que una de las dificultades de los profesores para identificar las situaciones de maltrato deriva del lugar y el momento donde suceden, dado que no suelen ocurrir delante de ellos, sino en lugares sin supervisión adulta, como por ejemplo la zona de recreo, los baños o los pasillos del centro, entre clase y clase. Por otra parte, la falta de correspondencia entre la percepción de maltrato físico que tiene el profesor y las diferentes variables de acoso estimadas es más evidente para el grupo de chicas y los alumnos de primaria. En el caso del grupo de chicas, nuestros resultados estarían de acuerdo con los planteamientos que sugieren la existencia de formas de acoso específicas vinculadas al sexo de los acosadores, según los cuales los chicos suelen agredir físicamente con mayor frecuencia que las chicas (Carbonell, 1999; Ortega, 1998), y las chicas suelen ser víctimas de la intimidación física en una proporción inferior a la mitad de los chicos (Rigby, 1997), lo que podría explicar que el 
profesor no tuviera conocimiento de esta forma de maltrato, o lo tuviera de forma muy limitada. Por otra parte, en relación con los alumnos de primaria, la agresión física podría ser interpretada por los profesores como una conducta normal para esta fase del desarrollo (Benítez, Fernández y Berbén, 2005), y por tanto restando importancia a este tipo de agresiones en los niños de menor edad.

Los datos sugieren que el CAI (conductas de acoso) posee unas propiedades psicométricas apropiadas y puede ser de utilidad para la evaluación multidimensional de las conductas de acoso desde el punto de vista de la victimización. Las conductas de acoso entre iguales, al igual que otras formas de maltrato, poseen un efecto nefasto sobre la salud del niño y adolescente (p.ej., Kokoulina y Fernández, 2014; Rodríguez, del Barrio, y Carrasco, 2013; Sandín, 1997; Sandín, Chorot y Valiente, 2016; Quiceno, Mateus, Cárdenas, Villarreal, y Vinaccia, 2013; Valiente, Sandín, y Chorot, 2003). El cuestionario pude resultar particularmente útil, tanto en contextos clínicos como de investigación, cuando se pretenda tener una medida comprensiva sobre la percepción del bullying que experimentan los niños víctimas del acoso escolar. Considerando que en los niños y adolescentes son frecuentes, tanto los miedos (Sandín, Chorot, Valiente y Santed, 1998; Valiente, Sandín y Chorot, 2002a,b; Valiente, Sandín, Chorot y Tabar, 2002, 2003), como los síntomas de los trastornos de ansiedad y depresión (Sandín et al., 2010; Sandín, Valiente y Chorot, 2009), futuros estudios deberían examinar la posible influencia de los diferentes tipos de bullying sobre estos síntomas psicopatológicos que se dan en la población infantojuvenil.

El presente trabajo posee algunas limitaciones obvias. Por una parte, aunque se centra en la percepción que tiene el niño del acoso escolar, los cuestionarios de autoinforme pueden tener cierto sesgo y sobrevalorar el nivel real del bullying. Por otra parte, no todas las subescalas del CAI-CA tienen la misma consistencia interna (fiabilidad). En concreto, las subescalas de ciberbullying, exclusión social directa, y agresión basada en objetos poseen niveles moderados del coeficiente alfa, aunque en otras medidas de la fiabilidad resultan más favorables. Tal vez sería deseable incrementar el número de items de estas subescalas en estudios futuros, con objeto de aumentar su consistencia interna. Finalmente, sería deseable validar empíricamente las restantes escalas del CAI, i.e., las escalas referidas a los escenarios en los que se produce el acoso, los personajes (personas implicadas diferentes a la víctima), el afrontamiento, los confidentes, y los síntomas de estrés postraumático.

\section{Referencias}

Ahmad, Y., \& Smith, P. K. (1990). Behavioural measures: Bullying in schools. Newsletter of Association for Child Psychology and Psychiatry, 12, 26-27.

Avilés, J. M. (1999). CIMEI. Cuestionario sobre intimidación y maltrato entre iguales. Valladolid: Autor.

Avilés, J. M. (2010). Cibullquest. Cuestionario de ciberbullying. Valladolid: Autor.

Benítez, J. L., Fernández, M., y Berbén, A.B.G. (2005). Conocimiento y actitud del maltrato entre alumnos (Bullying) de los futuros docentes de educación infantil, primaria y secundaria. Revista de Enseñanza Universitaria, 26.

Bentler, P. M. (1995). EQS Structural equations program manual. Encino, CA: Multivariate Software, Inc.

Boulton, M. J. (1997). Teacher's views on bullying: Definitions, attitudes and ability to COPE. British Journal of Educational Psychology, 67 (2), 223-233.

Buelga, S., Cava M. J., y Musitu G. (2010). Cyberbullying: victimización entre adolescentes a través del teléfono móvil y de internet. Psicothema, 22 (4), 784-789.

Carbonell, J. L. (1999). Programa para el desarrollo de la convivencia y la prevención de la violencia escolar. Madrid: Dirección Provincial del Ministerio de Educación y Cultura.

Catell, R. B. (1966). The screen test for the number of factors. Multivariate Behavioural Research, 3, 245-246.

Díaz-Aguado, M. J., Martínez, R., y Martín, G. (2004). Prevención de la violencia y lucha contra la exclusión desde la adolescencia, Vol. 1: La violencia entre iguales en la escuela y en el ocio. Estudios comparativos e instrumentos de evaluación. Madrid: Instituto de la Juventud.

Fu, Q., Land, K. C., \& Lamb, V. L. (2013). Bullying victimization, socioeconomic status and behavioral characteristics of 12 th graders in the United States, 1989 to 2009: Repetitive trends and persistent risk differentials. Child Indicators Research, 6 (1), $1-21$.

Funk, W. (1997). Violencia escolar en Alemania: estado de la cuestión. Revista de Educación, 313, 53-78.

Garaigordobil, M. (2014). Programa de intervención para prevenir y reducir el ciberbullying. Madrid: Pirámide.

Genta, M. L., Smithe, P. K. Ortega, R., Brighi, A., Guarini, A., Thompson, F., \& Calmaestra, J. (2012). Comparative aspects of cyberbullying in Italy, England and Spain: Findings from a DAPHNE Project. In Q. Li, D. Cross, \& P. K. Smith (Eds.), Cyberbullying in the global playground: research from international perspectives (pp. 15-31). Chichester: John Wiley and Sons.

Genta, M. L., Menesini, E., Fonzi, A., Costabile, A., \& Smith, P. (1996). Bullies and victims in schools in Central and Southern Italy. European Journal of Psychology of Education, 11 (1), 97-110.

Gorsuch, R. (1983). Factor analysis. Hillsdale, NJ: Erlbaum.

Hansen, T. B., Steenberg, L. M., Palic, S., \& Elklit, A. (2012). A review of psychological factors related to bullying victimization in schools. Aggression and Violent Behavior, 17(4), 383-387.

Hazler, R. J., Miller, D. L., Carney, J. V., \& Green, S. (2001). Adult recognition of school bullying situations. Educational Research, 43 (2), 133-146. 
Kokoulina, E., y Martínez, R. F. (2014). Maltrato físico y emocional durante la infancia y conducta suicida en el adulto. Revista de Psicopatología y Psicología Clínica, 19, 93-103.

Magaz, A. (2012). El maltrato entre iguales (bullying): Epidemiología y características psicológicas y sociodemográficas. Tesis doctoral. Universidad Nacional de Educación a Distancia (no publicada).

Magaz, A. M., Chorot, P., Sandín, B., Santed, M. A., y Valiente, R. M. (2011). Estilos de apego y acoso entre iguales (bullying) en adolescentes. Revista de Psicopatología y Psicología Clínica, 16, 207-221.

Mynard, H., \& Joseph, S. (2000). Development of the Multidimensional Peer-Victimization Scale. Aggressive Behaviour, 26, 169-178.

Nansel, T. R., Overpeck, M., Pilla. R. S., Ruan, W. J., Simons-Morton, B., \& Scheidt, P. (2001). "Bullying behaviours among US youth: Prevalence and association with psychosocial adjustment". Journal of the American Medical Association, 285, 2094-2100.

Olweus, D. (1973). Hakkycklingar och översittare. Forskning om skolmobbning. Estocolmo: Almqvist \& Wicksell.

Olweus, D. (1986). Mobbning -vad vi vet och vad vi kan göra. Estocolmo: Liber.

Olweus, D. (1996). The Revised Olweus Bully/Victim Questionnaire. Bergen (Norway): Mimeo.

Olweus, D. (1998). Conductas de acoso y amenaza entre escolares. Madrid: Morata.

Ortega, R. (1998). Trabajo con víctimas, agresores y espectadores de la violencia. La convivencia escolar: Qué es y cómo abordarla. Sevilla: Conserjería de Educación y Ciencia. Junta de Andalucía.

Ortega, R., Mora, J., y Mora-Merchán, J. A. (1995). Cuestionario sobre intimidación y maltrato entre iguales. Sevilla: Universidad de Sevilla.

Piñuel, I., y Oñate, A. (2006). AVE. Acoso y violencia escolar. Madrid: TEA.

Quiceno, J. M., Mateus, J., Cardenas, M., Villareal, D., y Vinaccia, S. (2013). Calidad de vida, resiliencia e ideación suicida en adolescentes víctimas de abuso sexual. Revista de Psicopatología y Psicología Clínica, 18, 107-117.

Rigby, K. (1997). What children tell us about bullying in schools? Children Australia, 22, 28-34.

Rodríguez, M. A., Del Barrio, M. V., y Carrasco, M. A. (2013). Agresión física y verbal en hijos de familias monoparentales divorciadas y biparentales: El efecto moderador del sexo de los hijos. Revista de Psicopatología y Psicología Clínica, 18(2), 119-127.

Sandín, B. (1997). Ansiedad, miedos y fobias en niños y adolescentes. Madrid: Dykinson.

Sandín, B. (2003). Diagnóstico de los trastornos de ansiedad: Manual para la ADIS-IV: C/P. Madrid: Klinik.

Sandín, B., y Chorot, P. (2003). Cuestionario de Afrontamiento del Estrés (CAE): Desarrollo y validación preliminar. Revista de Psicopatología y Psicología Clínica, 8, 39-53.

Sandín, B., Chorot, P., y Valiente, R. M. (2016). TCC de los trastornos de ansiedad: Innovaciones en niños y adolescentes. Madrid: Klinik.

Sandín, B., Chorot, P., Valiente, R. M., \& Chorpita, B. F. (2010). Development of a 30-ítem version of the Revised Child Anxie- ty and Depression Scale. Revista de Psicopatología y Psicología Clínica, 15, 165-178.

Sandín, B., Chorot, P., Valiente, R. M., y Santed, M. A. (1998). Frecuencia e intensidad de los miedos en los niños: Datos normativos. Revista de Psicopatología y Psicología Clínica, 3, 15-25.

Sandín, B., Chorot, P., Valiente, R. M., Santed, M. A., Olmedo, M., Pineda, D., y Campagne, D. (2013). Construcción y validación preliminar de la Escala Multidimensional de Sensibilidad al Asco (EMA). Revista de Psicopatología y Psicología Clínica, 18, 1-18

Sandín, B., Valiente, R. M., y Chorot, P. (2009). RCADS: Evaluación de los síntomas de los trastornos de ansiedad y depresión en niños y adolescentes. Revista de Psicopatología y Psicología Clínica, 14, 193-206.

Silverman, W. K., Albano, A. M., y Sandín, B. (2003). Entrevista para el Diagnóstico de los Trastornos de Ansiedad en Niños (ADIS-IV: C): Entrevista para el niño. Madrid: Klinik.

Silverman, W. K., Albano, A. M., y Sandín, B. (2003). Entrevista para el Diagnóstico de los Trastornos de Ansiedad en Niños (ADIS-IV: P): Entrevista para los padres. Madrid: Klinik.

Shakeshaft, C., Barber, E., Hergenrother, M. A., Johnson, Y. M., Mandel, L. S., \& Sawyer, J. (1995). Peer harassment in schools. Journal for a just and Caring Education, 1, 30-44.

Slonje, R., Smith, P. K., \& Frisén, A. (2013). The nature of cyberbullying, and strategies for prevention. Computers in Human Behavior, 29(1), 26-32.

Smith, P. K., \& Sharp, S. (1994). School bullying: insights and perspectives. Londres: Routledge.

Solberg, M., \& Olweus, D. (2003). Prevalence estimation of school bullying with the Olweus Bully/Victim Questionnaire. Aggressive Behaviour, 29, 239-268.

Sullivan, K., Cleary, M., \& Sullivan, G. (2003). Bullying en la enseñanza secundaria. El acoso escolar cómo se presenta y cómo afrontarlo. Qué sabemos sobre el acoso escolar en la enseñanza secundaria. Madrid: Ediciones CEAC.

Thurstone, L. L. (1947). Multiple-factor analysis. Chicago: University. Chicago Press.

Undheim, A. M., \& Sund, A. M. (2010). Prevalence of bullying and aggressive behavior and their relationship to mental health problems among 12 to 15 -year-old Norwegian adolescents. European Child \& Adolescent Psychiatry, 19, 803-811.

Valiente, R. M., Sandín, B., y Chorot, P. (2002). Miedos comunes en niños y adolescentes: Relación con la sensibilidad a la ansiedad, el rasgo de ansiedad, la afectividad negativa y la depresión. Revista de Psicopatología y Psicología Clínica, 7, 61-70.

Valiente, R. M., Sandín, B., y Chorot, P. (2002). Miedos comunes en niños y adolescentes: Su relación con la sensibilidad a la ansiedad y otras emociones negativas. Psiquis, 23, 217-225.

Valiente, R. M., Sandín, B., y Chorot, P. (2003). Miedos en la infancia y la adolescencia. Madrid: Editorial UNED.

Valiente, R. M., Sandín, B., Chorot, P., y Tabar, A. (2002). Diferencias sexuales en la prevalencia e intensidad de los miedos durante la infancia y la adolescencia: Datos basados en el FSSC-R. Revista de Psicopatología y Psicología Clínica, 7, 103-113.

Valiente, R. M., Sandín, B., Chorot, P., y Tabar, A. (2003). Diferencias según la edad en la prevalencia e intensidad de los miedos durante la infancia y la adolescencia: Datos basados en el FSSC-R. Psicothema, 15, 414-419. 


\section{Anexo I \\ Cuestionario de Acoso entre Iguales (CAI)}

Instrucciones: A continuación encontrarás una serie de frases sobre formas de comportarse contigo que tienen otros chicos o chicas del colegio. Tu tarea consiste en marcar con una $\mathbf{X}$ el cuadrado que indique lo que a ti te ha ocurrido durante este curso y el anterior. A cada pregunta hay que dar solo una respuesta.

\section{Ejemplo:}
Me roban cosas
NUNCA
凶 POCAS VECES
$\square$ MUCHAS VECES

\section{CAI-Conductas de Acoso (CAI-CA)}

\begin{tabular}{|c|c|c|c|}
\hline 1. Me pegan collejas & $\square$ NUNCA & $\square$ POCAS VECES & $\square$ MUCHAS VECES \\
\hline 2. Me pegan puñetazos & $\square$ NUNCA & $\square$ POCAS VECES & $\square$ MUCHAS VECES \\
\hline 3. Me pegan patadas & $\square$ NUNCA & $\square$ POCAS VECES & $\square$ MUCHAS VECES \\
\hline 4. Me pegan con objetos (por ejemplo, palos, tijeras, piedras, etc.) & $\square$ NUNCA & $\square$ POCAS VECES & $\square$ MUCHAS VECES \\
\hline 5. Me insultan & $\square$ NUNCA & $\square$ POCAS VECES & $\square$ MUCHAS VECES \\
\hline 6. Me impiden jugar con ellos & $\square$ NUNCA & $\square$ POCAS VECES & $\square$ MUCHAS VECES \\
\hline 7. Me amenazan con que me pegan & $\square$ NUNCA & $\square$ POCAS VECES & $\square$ MUCHAS VECES \\
\hline 8. Me dejan de hablar & $\square$ NUNCA & $\square$ POCAS VECES & $\square$ MUCHAS VECES \\
\hline 9. Me llaman con un nombre que no me gusta (cuatro ojos, bola, enano, palillo, etc.) & $\square$ NUNCA & $\square$ POCAS VECES & $\square$ MUCHAS VECES \\
\hline 10. Me amenazan con objetos (por ejemplo, palos, tijeras, piedras, etc.) & $\square$ NUNCA & $\square$ POCAS VECES & $\square$ MUCHAS VECES \\
\hline 11. Me mandan callar & $\square$ NUNCA & $\square$ POCAS VECES & $\square$ MUCHAS VECES \\
\hline 12. Me acusan de cosas que no he dicho o hecho & $\square$ NUNCA & $\square$ POCAS VECES & $\square$ MUCHAS VECES \\
\hline 13. Me empujan & $\square$ NUNCA & $\square$ POCAS VECES & $\square$ MUCHAS VECES \\
\hline 14. Les dicen a otros que no estén o que no hablen conmigo & $\square$ NUNCA & $\square$ POCAS VECES & $\square$ MUCHAS VECES \\
\hline 15. Me dicen que se van a "chivar de mí" & $\square$ NUNCA & $\square$ POCAS VECES & $\square$ MUCHAS VECES \\
\hline 16. Me esconden cosas & $\square$ NUNCA & $\square$ POCAS VECES & $\square$ MUCHAS VECES \\
\hline 17. Les prohíben a otros que jueguen conmigo & $\square$ NUNCA & $\square$ POCAS VECES & $\square$ MUCHAS VECES \\
\hline 18. Me gritan & $\square$ NUNCA & $\square$ POCAS VECES & $\square$ MUCHAS VECES \\
\hline 19. Me rompen cosas & $\square$ NUNCA & $\square$ POCAS VECES & $\square$ MUCHAS VECES \\
\hline 20. Me roban cosas & $\square$ NUNCA & $\square$ POCAS VECES & $\square$ MUCHAS VECES \\
\hline 21. Me impiden jugar con otros niños & $\square$ NUNCA & $\square$ POCAS VECES & $\square$ MUCHAS VECES \\
\hline 22. Se ríen de mí cuando me equivoco & $\square$ NUNCA & $\square$ POCAS VECES & $\square$ MUCHAS VECES \\
\hline 23. Me ocultan a dónde van & $\square$ NUNCA & $\square$ POCAS VECES & $\square$ MUCHAS VECES \\
\hline 24. Me ponen la zancadilla & $\square$ NUNCA & $\square$ POCAS VECES & $\square$ MUCHAS VECES \\
\hline 25. Me pellizcan & $\square$ NUNCA & $\square$ POCAS VECES & $\square$ MUCHAS VECES \\
\hline 26. Me tiran del pelo & $\square$ NUNCA & $\square$ POCAS VECES & $\square$ MUCHAS VECES \\
\hline 27. Me envían mensajes de móvil o correos electrónicos para insultarme o amenazarme & $\square$ NUNCA & $\square$ POCAS VECES & $\square$ MUCHAS VECES \\
\hline 28. Cuando chateo con otros niños, se meten conmigo & $\square$ NUNCA & $\square$ POCAS VECES & $\square$ MUCHAS VECES \\
\hline 29. Me hacen fotos o me graban con el móvil mientras se meten conmigo & $\square$ NUNCA & $\square$ POCAS VECES & $\square$ MUCHAS VECES \\
\hline 30. Se burlan colgando fotos o vídeos sobre mí en internet & $\square$ NUNCA & $\square$ POCAS VECES & $\square$ MUCHAS VECES \\
\hline
\end{tabular}




\begin{tabular}{l|c|c}
\hline 31. Me mienten para que no vaya con ellos. & $\square$ NUNCA & $\square$ POCAS VECES \\
\hline 32. Me tiran cosas (por ejemplo, pelotas de papel, cosas de clase, piedras, etc.) & $\square$ NUNCA & $\square$ POCAS VECES \\
\hline 33. Me amenazan para que diga cosas que no quiero & $\square$ NUNCA & $\square$ POCAS VECES \\
\hline 34. No quieren hacer trabajos conmigo & $\square$ NUNCA & $\square$ POCAS VECES \\
\hline 35. Me amenazan con contar cosas de mí o de mi familia & $\square$ NUNCA & $\square$ POCAS VECES \\
\hline 36. No se quieren sentar conmigo & $\square$ NUNCA & $\square$ POCAS VECES \\
\hline $\begin{array}{l}\text { 37. Hacen cosas para molestarme (se ponen en medio, no me dejan pasar, me des- } \\
\text { peinan, cada vez que pasan por mi lado me tocan, etc.) }\end{array}$ \\
\hline $\begin{array}{l}\text { 38. Me hacen gestos para meterse conmigo o asustarme } \\
\text { Me POCAS VECES }\end{array}$ \\
\hline $\begin{array}{l}\text { 39. Me amenazan para que haga cosas que no quiero (darles dinero, dejarles copiar } \\
\text { mis deberes, hacer bromas pesadas y otras cosas) }\end{array}$ \\
\hline
\end{tabular}

\section{Sólo si eres chica contesta a las siguientes preguntas (CAI-CAG)}

45. Van diciendo que voy con muchos chicos

46. Me llaman marimacho

47. Se meten conmigo porque no gusto a los chicos

48. Se meten conmigo porque me gustan cosas y juegos de chicos

49. Dicen a otros que soy fea

\begin{tabular}{|c|c|c}
$\square$ NUNCA & $\square$ POCAS VECES & $\square$ MUCHAS VECES \\
$\square$ NUNCA & $\square$ POCAS VECES & $\square$ MUCHAS VECES \\
$\square$ NUNCA & $\square$ POCAS VECES & $\square$ MUCHAS VECES \\
$\square$ NUNCA & $\square$ POCAS VECES & $\square$ MUCHAS VECES \\
$\square$ NUNCA & $\square$ POCAS VECES & $\square$ MUCHAS VECES
\end{tabular}

\section{Sólo si eres chico contesta a las siguientes preguntas (CAI-CAG)}

50. Van diciendo que no voy con chicas

\section{Me llaman "nenaza"}

52. Se meten conmigo porque no gusto a las chicas

53. Se meten conmigo porque me gustan las cosas y juegos de chicas

54. Dicen a otros que soy feo

\begin{tabular}{l|l|c}
$\square$ NUNCA & $\square$ POCAS VECES & $\square$ MUCHAS VECES \\
$\square$ NUNCA & $\square$ POCAS VECES & $\square$ MUCHAS VECES \\
$\square$ NUNCA & $\square$ POCAS VECES & $\square$ MUCHAS VECES \\
\hline NUNCA & $\square$ POCAS VECES & $\square$ MUCHAS VECES \\
\hline NUNCA & $\square$ POCAS VECES & $\square$ MUCHAS VECES \\
\hline
\end{tabular}

\section{CAI-Escenarios (CAI-E)}

¿Dónde te ocurren estas cosas? Rodea con un círculo el SI o el NO

\begin{tabular}{l|l|l}
\hline 1. En la clase de gimnasia cuando está algún profesor/a & SI & NO \\
\hline 2. En las demás clases cuando está algún profesor/a & SI & NO \\
\hline 3. En la clase de gimnasia cuando no hay ningún profesor/a & SI & NO \\
\hline 4. En las demás clases cuando no hay ningún profesor/a & SI & NO \\
\hline 5. En los pasillos & SI & NO \\
\hline 6. En el comedor & SI & NO \\
\hline 7. En los aseos & SI & NO \\
\hline 8. En el patio cuando vigila algún profesor/a & SI & NO \\
\hline 9. En el patio cuando no vigila ningún profesor/a & SI & NO \\
\hline 10. Al salir de clase, cerca del colegio & SI & NO \\
\hline 11. En las actividades extraescolares (natación, fútbol, teatro, etc.) & SI & NO \\
\hline 12. En la calle & SI & NO \\
\hline 13. En el autobús escolar & SI & NO \\
\hline 14. Andando, de camino a casa & SI & NO \\
\hline
\end{tabular}




\section{CAI-Personajes (CAI-P)}

¿Quién suele hacer estas cosas? Rodea con un círculo el SI o el NO

\begin{tabular}{l|c|c}
\hline 1. Chicos de mi misma clase & SI & NO \\
\hline 2. Chicas de mi misma clase & SI & NO \\
\hline 3. Chicos de cursos superiores al mío & SI & NO \\
\hline 4. Chicas de cursos superiores al mío & SI & NO \\
\hline 5. Chicos de cursos inferiores al mío & SI & NO \\
\hline 6. Chicas de cursos inferiores al mío & SI & NO \\
\hline 7. ¿Hay algún compañero que te defiende? & SI & NO \\
\hline 8. ¿Hay algún adulto que te defiende? & SI & NO \\
\hline 9. ¿Hay compañeros que se quedan mirando sin hacer nada? & SI & NO \\
\hline 10. ¿Hacen estas cosas con más compañeros? & SI & NO \\
\hline 15. ¿Cuántos suelen ser los que se meten conmigo? & & \\
\hline
\end{tabular}

\section{CAI-Afrontamiento (CAI-A)}

¿Qué has intentado hacer para solucionar estas cosas? Rodea con un círculo el SI o el NO

\begin{tabular}{l|l|l}
\hline 1. Les respondo de la misma forma que ellos se meten conmigo & SI & NO \\
\hline 2. Nada, porque creo que esta situación nunca se va a solucionar & SI & NO \\
\hline 3. Evito encontrarme a los compañeros que me pegan, se burlan o se meten conmigo & SI & NO \\
\hline 4. Paso de ellos, no les hago caso & SI & NO \\
\hline 5. Pienso que ya se cansarán & SI & NO \\
\hline 6. Pienso que dejaré de verles & SI & NO \\
\hline 7. Pienso o le pido a mis padres que me cambien de colegio & SI & NO \\
\hline 8. Me apunto a clases para aprender a defenderme (karate, judo, etc.) & SI & NO \\
\hline
\end{tabular}

Escribe otras cosas que hayas intentado hacer que no estén en esta lista

\section{CAI-Confidentes}

¿Has hablado con alguien de estas cosas? Rodea con un círculo el SI o el NO

\begin{tabular}{l|l|l}
\hline 1. Con tu padre & SI & NO \\
\hline 2. Con tu madre & SI & NO \\
\hline 3. Con tus hermanos & SI & NO \\
\hline 4. Con tus compañeros o amigos de clase & SI & NO \\
\hline 5. Con otros amigos de la calle o barrio & SI & NO \\
\hline 6. Con nadie, me lo callo & SI & NO \\
\hline
\end{tabular}




\section{CAI-Estrés postraumático (CAI-EP)}

¿Cómo te afectan estas cosas? Rodea con un círculo el SI o el NO

1. ¿De repente te vienen a la cabeza pensamientos sobre que se meten contigo, te pegan, te insultan, no te hacen caso u otras cosas parecidas?

2. ¿Has soñado o tienes pesadillas donde ves que tus compañeros se meten contigo, te pegan, te insultan, no te hacen caso, etc.?

Cuando te acuerdas de que tus compañeros se meten contigo, te pegan, te insultan, etc. ¿qué te ocurre?

3. ¿Te sientes muy mal?

4. ¿Tienes sensaciones desagradables como temblores, sudor, tu corazón late muy deprisa?

\begin{tabular}{|l|l}
\hline SI & NO \\
\hline SI & NO
\end{tabular}

Desde que tus compañeros se meten contigo, te pegan, te insultan, no te hacen caso u otras cosas parecidas ¿qué te ocurre?

5. ¿Tienes dificultad para dormir?

6. ¿Tienes dificultad para atender en clase?

7. ¿Tienes mal genio, rabietas, enfados?

8. ¿Te sientes tenso, como preparado por si ocurriera algo malo?

9. ¿Tienes menos ganas de ver a tus amigos?

10. ¿Tienes menos ganas de jugar o hacer otras cosas que antes te gustaba hacer?

11. ¿Intentas no pensar en los sitios donde te ocurren estas cosas?

\begin{tabular}{l|l} 
SI & NO \\
\hline SI & NO \\
\hline SI & NO \\
\hline SI & NO \\
\hline SI & NO \\
\hline SI & NO \\
\hline SI & NO \\
\hline
\end{tabular}


